\title{
The association between suicide deaths and putatively harmful and protective factors in media reports
}

\author{
Mark Sinyor MSc MD, Ayal Schaffer MD, Yasunori Nishikawa, Donald A. Redelmeier MD, \\ Thomas Niederkrotenthaler MD PhD, Jitender Sareen MD, Anthony J. Levitt MD, Alex Kiss PhD, Jane Pirkis PhD
}

Cite as: CMAJ 2018 July 30;190:E900-7. doi: 10.1503/cmaj.170698

See related article at www.cmaj.ca/lookup/doi/10.1503/cmaj.180900

\begin{abstract}
BACKGROUND: Exposure to media reporting on suicide can lead to suicide contagion and, in some circumstances, may also lead to help-seeking behaviour. There is limited evidence for which specific characteristics of media reports mediate these phenomena.
\end{abstract}

METHODS: This observational study examined associations between putatively harmful and protective elements of media reports about suicide in 13 major publications in the Toronto media market and subsequent suicide deaths in Toronto (2011-2014). We used multivariable logistic regression to determine whether specific article characteristics were associated with increases or decreases in suicide deaths in the 7 days after publication, compared with a control window.

RESULTS: From 2011 to 2014, there were 6367 articles with suicide as the major focus and 947 suicide deaths. Elements most strongly and independently associated with increased suicides were a statement about the inevitability of suicide (odds ratio [OR] 1.97, confidence interval $[\mathrm{Cl}]$ 1.07-3.62), about asphyxia by a method other than car exhaust (OR 1.72, Cl 1.36-2.18), about suicide by jumping from a building (OR 1.70, Cl 1.28-2.26) or about suicide pacts (OR 1.63, Cl 1.14-2.35), or a headline that included the suicide method (OR $1.41, \mathrm{Cl}$ 1.07-1.86). Elements most strongly and independently associated with decreased suicides were unfavourable characteristics (negative judgments about the deceased; OR 1.85, $\mathrm{Cl} 1.20$ 2.84 ), or mentions of railway (OR $1.61, \mathrm{Cl}$ 1.10-2.36) and cutting or stabbing (OR 1.59, $\mathrm{Cl} 1.19-2.13)$ deaths, and individual murder-suicide (OR 1.50, Cl 1.23-1.84).

INTERPRETATION: This large study identified significant associations between several specific elements of media reports and suicide deaths. It suggests that reporting on suicide can have a meaningful impact on suicide deaths and that journalists and media outlets and organizations should carefully consider the specific content of reports before publication. uicide is a major, global public health issue that accounts for at least 800000 deaths per year worldwide. ${ }^{1}$ A substantial body of literature shows that media reports relating to suicide can influence some people to end their lives. ${ }^{2-12}$ This phenomenon, known as the Werther effect, is thought to occur via social learning, whereby a vulnerable person identifies with someone portrayed in the media and copies his or her behaviour..$^{5-7,13-21}$ Studies in Australia, Austria and the United States have identified potentially harmful elements of media reporting associated with increased rates of subsequent suicide. ${ }^{5,6,21}$ These include repetitive reporting, front-page story placement, reports about suicides by jumping, suicide death (rather than ideation or attempts), suicide pacts, including the word "suicide" or the suicide method in the headline, accompanying photos, "monocausal" (single cause and effect) explanations for suicide, and reports that included misinformation ("public myths") about suicide. ${ }^{5,6,21}$ However, these elements were not tested or significant in all studies.

A second phenomenon, called the Papageno effect, has been proposed whereby protective factors in reports on suicide may lead readers to initiate adaptive behaviours, resulting in fewer suicide deaths. ${ }^{5}$ In Austria, newspaper articles depicting "mastery of suicide," in which people experienced suicidal ideation but found solutions other than suicidal behaviour, were associated with decreased subsequent suicides. ${ }^{5}$

Responsible media reporting is one of a limited number of strategies, which also include restriction of means and schoolbased awareness programs, that may affect suicide rates at a population level.22-24 Worldwide, numerous guidelines have been developed to advise the media on best practices. ${ }^{25-29}$ Journalists and media organizations can modify their content and are tasked with the challenge of balancing concerns about contagion with the 
public's right to be informed. ${ }^{30}$ A detailed understanding of the specific aspects of media reports that may provoke suicide contagion is needed to help the media make these decisions; however, evidence identifying the "active ingredients" in media reporting that may mediate suicide contagion or adaptive behaviour remains limited. The studies above have established an evidentiary starting point from which the relative harmful or protective contributions of specific elements in media reports may begin to be unpacked. However, replication of findings across regions and cultures is also needed. The aim of this study is a comprehensive examination of the impact of putatively harmful and protective content of suicide reporting in print and online media on suicide death in Toronto, Canada's largest urban centre.

\section{Methods}

\section{Media data}

Print and online media reports relating to suicide in the Toronto media market from 2011 to 2014 were the exposure of interest. We identified the 12 major Canadian publications that account for the large majority of traditional news circulation in the Toronto market, and 1 US newspaper with high circulation in Toronto (Box 1). Because of the large volume of articles, we hired Infomart, Canada's leading media consultancy; the study investigators trained Infomart personnel to identify and code articles using an electronic database (for full details, see Appendix 1, available at www. cmaj.ca/lookup/suppl/doi:10.1503/cmaj.170698/-/DC1).

\section{Coding and abstraction strategy}

Articles were coded for content (Appendix 1). We explicitly derived putatively harmful and protective elements from 2009 Canadian Psychiatric Association reporting guidelines for media. ${ }^{29}$

We coded all variables independently of each other. That is, an article could be coded as being about suicide in both men and women if both were described. Likewise, an article that included both a statement of approval of suicide and a message of hope

Box 1: Publications included in the analysis $(n=13)$

Canadian newspapers and their online platforms:

- The Globe \& Mail: theglobeandmail.com

- The National Post: nationalpost.com

- The Toronto Star: thestar.com

Two other Canadian newspapers:

- The Toronto Sun

- 24 Hours Toronto

One magazine:

- Maclean's

Three websites:

- CBC.ca

- canada.com

- financialpost.com

One US newspaper:

- The New York Times would have been coded as having both. Given the potential subjectivity inherent to some of these categorizations (e.g., whether an article included glorified or romanticized reasons for the suicide), we conducted inter-rater reliability tests, all of which included both a scientific content expert and an expert in journalism. We corresponded and held regular meetings throughout the process of abstraction to clarify points of uncertainty. We performed reliability tests initially, after every approximately 1000 articles coded, and at completion (for $\mathrm{k}$ values, see Appendix 2, available at www.cmaj. ca/lookup/suppl/doi:10.1503/cmaj.170698/-/DC1).

\section{Suicide deaths}

The population of suicide deaths includes a consecutive list of people whom the Office of the Chief Coroner of Ontario determined to have died by suicide in the city of Toronto between Jan. 1, 2011 and Dec. 31, 2014, inclusive. Detailed methods of data abstraction of the Office of the Chief Coroner have been published previously (Appendix 1). ${ }^{31}$

\section{Statistical analysis}

We conducted analyses only on "major focus" articles (Appendix 1) from 2011 to 2014. The primary outcome variable of interest was the difference $(\Delta)$ between the number of suicide deaths in the week after publication (this post-item period included the date of publication - "day 0" - and 6 subsequent days) compared with a pre-item control window with a 1-week lag ( $d-14$ to -8$)$ to ensure separation from other media reports of the same event that might have occurred just before day 0 . We tested the impact of the volume of reports by including a continuous variable - a count of all articles relating to suicide published between day -14 and day 0 .

We first conducted bivariate analyses under 2 conditions. Following previously established methods, ${ }^{5,6}$ article characteristics were compared for $\Delta>0$ (i.e., periods in which there were more suicide deaths after the article) versus $\Delta \leq 0$ (i.e., periods where there were the same number or fewer deaths after the article). We did this to test for a potential harmful effect. We conducted a second set of bivariate comparisons to test for a potential protective effect, this time comparing $\Delta<0$ to $\Delta \geq 0$, to identify article characteristics associated with fewer suicide deaths subsequent to publication.

The primary analyses involved 2 multivariable logistic regressions to determine the independent predictive contributions of media content characteristics on bivariate change in suicide deaths, the first for harmful and the second for protective associations. We included the variables that were significant in their respective bivariate analyses. We determined multicollinearity via tolerance $(<0.40)$ and variance inflation factor $(<2.5)$ values. We performed sensitivity analyses to test the impact of print versus online publications, as well as early (2011-2012) versus late (2013-2014) publication.

Significance was determined at a threshold of 0.05 for all variables.

\section{Ethics approval}

This study was approved by the Sunnybrook Health Sciences Centre research ethics board (ID\# 199-2012). 


\section{Results}

From 2011 to 2014, there were 16845 articles relating to suicide across the 13 publications, including 6367 (37.8\%) in which suicide was the major focus of the article ( $41.9 \%$ of these were online). Of the major focus subset, 314 (4.9\%) appeared on the front page and $1736(27.3 \%)$ included the word "suicide" in the headline. Over the same span, there were 947 suicide deaths (mean deaths per year \pm standard deviation: $236.8 \pm 22.6$ ) in Toronto (demographic and suicide-specific characteristics shown in Table 1).

\section{Bivariate comparisons}

Tables 2 and 3 show bivariate analyses testing for increases and decreases in suicide frequencies in the week following publication of articles with different general content and putatively harmful or protective elements, respectively, from 2011 to 2014. Elements associated with more suicides in both harmful and protective comparisons were articles that focused on older adults, suicide pacts, jumping from a building, firearm death, and asphyxia other than by car exhaust, as well as those that identified the deceased as a celebrity. Mention of the suicide method in the headline and in the text, as well as a statement that suicide is inevitable, were all associated with increased suicides in the harmful effect analysis.

A higher number of recent articles related to suicide was associated with decreased suicides in both the harmful effect (odds ratio [OR] 0.995, 95\% confidence interval [Cl] 0.994-0.996) and protective effect (OR 0.997, 95\% Cl 0.995-0.998) analyses. Other elements associated with fewer suicides in both comparisons were articles that focused on youth, a specific person's suicidality or death, public policy, railway deaths and cutting or stabbing deaths. Articles about a specific person's suicide death, articles about murdersuicide, articles with monocausal explanations for suicide, articles highlighting unfavourable characteristics of the deceased (i.e., characterological or personal flaws or criminality) and articles including interviews with bereaved people were all associated with a subsequent decrease in suicides in the protective effect analysis.

\section{Regression analyses}

For multivariable logistic regression, Hosmer-Lemeshow tests showed good model fit $(p<0.05)$ for the protective effect regression model with all variables included and for the harmful effect model only if the continuous measure of number of articles was removed. Independent predictors in the harmful and protective effect models are shown in Table 4 and Table 5, respectively. Elements significantly independently associated with increased suicides in the harmful effect model were articles that contained a statement that suicide is inevitable (OR 1.97, Cl 1.07-3.62); that were about asphyxia other than by car exhaust (OR 1.72, Cl 1.362.18), suicide by jumping from a building (OR $1.70, \mathrm{Cl} 1.28-2.26$ ), suicide pacts (OR 1.63, Cl 1.14-2.35), firearm suicide (OR 1.28, $\mathrm{Cl} 1.08-1.51$ ), or older adults (OR 1.25, $\mathrm{Cl} 1.03-1.52$ ); that included the suicide method in the headline (OR 1.41, Cl 1.07-1.86); or that identified the deceased as a celebrity (OR 1.27, $\mathrm{Cl} 1.08-1.49$ ). Elements significantly independently associated with decreased suicides in the protective effect model were unfavourable characteristics (OR 0.54, $\mathrm{Cl} 0.35-0.83$ ), railway (OR 0.62, $\mathrm{Cl} 0.42-0.91$ ) and cutting or stabbing (OR $0.63, \mathrm{Cl} 0.47-0.84$ ) deaths; individual murder-suicide (OR 0.67, Cl 0.54-0.82); or articles about a specific person's suicide or suicidality (OR $0.77, \mathrm{Cl} 0.66-0.89$ ), public policy (OR 0.84, $\mathrm{Cl} 0.72-0.97$ ) and youth (OR 0.85, $\mathrm{Cl} 0.75-0.96$ ).

Sensitivity analyses stratifying by media type and publication era are presented in Appendices 3 and 4 (available at www.cmaj. ca/lookup/suppl/doi:10.1503/cmaj.170698/-/DC1). Although these yielded some variability in elements that met the threshold for statistical significance, odds ratios were generally similar in direction and size between print and online articles, as well as 2011-2012 and 2013-2014 articles. An exception was articles about jumping from a building, which in 2011-2012 were associated with increased suicides in the harmful effect analysis (OR $2.47,95 \% \mathrm{Cl}$ $1.71-3.57$ ), but not in 2013-2014 (OR 0.83, 95\% Cl 0.51-1.34).

\section{Interpretation}

This study of the association between media reporting and suicide death found that several media item characteristics were associated with changes in suicides. Consistent with previous literature,

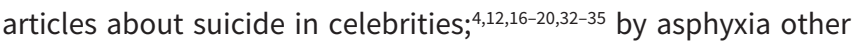
than by car exhaust (i.e., by plastic bag or helium gas, but not hanging or car exhaust) ${ }^{36-41}$ or by jumping; ${ }^{5,16}$ suicide pacts; ${ }^{21}$ and that included the method in the headline ${ }^{21}$ were each independently associated with post-item increases in suicides. It is

Table 1: Suicide deaths in Toronto by age and gender (2011-2014 combined)

$$
\begin{gathered}
\text { Total suicides } \\
n=947
\end{gathered}
$$

\begin{tabular}{|c|c|c|}
\hline Characteristic & No. of men (\%) & No. of women (\%) \\
\hline \multicolumn{3}{|l|}{ Age, yr } \\
\hline $10-24$ & $74(7.8)$ & $24(2.5)$ \\
\hline $25-44$ & $205(21.6)$ & $80(8.4)$ \\
\hline $45-64$ & $261(27.6)$ & $123(13.0)$ \\
\hline $65+$ & $130(13.7)$ & $50(5.3)$ \\
\hline Total & $670(70.7)$ & $277(29.3)$ \\
\hline \multicolumn{3}{|l|}{ Method of suicide } \\
\hline Hanging & $251(26.5)$ & $73(7.7)$ \\
\hline Non-hanging asphyxia & $58(6.1)$ & $14(1.5)$ \\
\hline Fall or jump from height & $158(16.7)$ & $76(8.0)$ \\
\hline Overdose & $96(10.1)$ & $88(9.3)$ \\
\hline Subway, train or car collision & $38(4.0)$ & $11(1.2)$ \\
\hline Firearm & $30(3.2)$ & $-{ }^{\star}$ \\
\hline Cutting or stabbing & $20(2.1)$ & $-^{\star}$ \\
\hline Drowning or hypothermia & $14(1.5)$ & $-{ }^{*}$ \\
\hline Fire, burns or electrocution & $-^{*}$ & $-^{*}$ \\
\hline Poisons: toxins & $-^{*}$ & $-^{*}$ \\
\hline Unknown & $-^{*}$ & $-*$ \\
\hline
\end{tabular}


particularly noteworthy that articles emphasizing the inevitability of suicide were associated with increased subsequent deaths.

Articles describing suicide in older adults were also positively associated with subsequent suicides. This may be because this population is more likely to be exposed to and therefore influenced by newspaper reports. ${ }^{42,43}$ Older adults are also over-represented among suicide deaths, accounting for nearly twice as many as youth (see Table 1), which may make a media effect easier to detect.
Reporting of firearm suicides, among the methods with the highest lethality, was associated with increased subsequent suicides, consistent with previous findings. ${ }^{36}$ Notably, although firearm suicides account for less than $5 \%$ of all deaths in Toronto, ${ }^{31}$ firearms were described as a method of suicide in $13 \%$ of articles. Furthermore, emerging evidence suggests that novel methods of asphyxia, such as helium inhalation, may be particularly prone to contagion, ${ }^{37-41}$ and the results here would seem to support that.

Table 2: Characteristics of articles focusing on suicide in major publications in Toronto media (2011-2014) and their association with increases or decreases in suicides after publication

\begin{tabular}{|c|c|c|c|c|c|c|}
\hline & & & & & $\begin{array}{l}\text { Harmful effect } \\
\text { analysis* }\end{array}$ & $\begin{array}{c}\text { Protective effect } \\
\text { analysis } \dagger\end{array}$ \\
\hline Characteristics of media item & $\begin{array}{c}\text { Total }(\%) \\
n=6367\end{array}$ & $\begin{array}{l}\text { No. of articles } \\
\text { followed by } \\
\text { increased } \\
\text { suicides (\%) }\end{array}$ & $\begin{array}{l}\text { No. of articles } \\
\text { followed by no } \\
\text { change in } \\
\text { suicides (\%) }\end{array}$ & $\begin{array}{l}\text { No. of articles } \\
\text { followed by } \\
\text { decreased } \\
\text { suicides (\%) }\end{array}$ & $\begin{array}{c}\text { Increased } v . \text { no } \\
\text { change or } \\
\text { decreased suicides } \\
\text { OR }(95 \% \mathrm{CI})\end{array}$ & $\begin{array}{c}\text { No change or } \\
\text { increased v. } \\
\text { decreased suicides } \\
\text { OR }(95 \% \mathrm{CI})\end{array}$ \\
\hline \multicolumn{7}{|l|}{ Item location } \\
\hline Front page & 314 (4.9) & $134(42.7)$ & $50(15.9)$ & $130(41.4)$ & $0.95(0.76-1.20)$ & $1.03(0.82-1.30)$ \\
\hline Online & $2667(41.9)$ & $1191(44.7)$ & $367(13.8)$ & 1109 (41.6) & $1.06(0.96-1.18)$ & $1.04(0.94-1.15)$ \\
\hline \multicolumn{7}{|l|}{ Age focus } \\
\hline Youth & $2014(31.6)$ & $836(41.5)$ & $268(13.3)$ & $910(45.2)$ & $0.87(0.79-0.97)$ & $0.83(0.75-0.93)$ \\
\hline Adult & 2029 (31.9) & $913(45.0)$ & $288(14.2)$ & $828(40.8)$ & $1.08(0.97-1.20)$ & $1.08(0.97-1.21)$ \\
\hline Older adults & $458(7.2)$ & $232(50.7)$ & $67(14.6)$ & $159(34.7)$ & $1.35(1.11-1.63)$ & $1.40(1.15-1.71)$ \\
\hline \multicolumn{7}{|l|}{ Gender focus } \\
\hline Male & $3417(53.7)$ & $1465(42.9)$ & $438(12.8)$ & $1514(44.3)$ & $1.05(0.94-1.16)$ & $0.94(0.85-1.04)$ \\
\hline Female & $2501(39.3)$ & $1076(43.0)$ & $360(14.4)$ & $1065(42.6)$ & $0.95(0.86-1.05)$ & $0.97(0.88-1.08)$ \\
\hline \multicolumn{7}{|l|}{ Suicide focus } \\
\hline Ideation & $1547(24.3)$ & $659(42.6)$ & $244(15.8)$ & $644(41.6)$ & $0.94(0.84-1.05)$ & $1.03(0.92-1.16)$ \\
\hline Attempt & $1079(16.9)$ & $467(43.3)$ & $158(14.6)$ & $454(42.1)$ & $0.98(0.86-1.11)$ & $1.00(0.88-1.15)$ \\
\hline Death & $4764(74.8)$ & $2062(43.3)$ & $650(13.6)$ & $2052(43.1)$ & $0.92(0.83-1.04)$ & $0.86(0.77-0.97)$ \\
\hline \multicolumn{7}{|l|}{ Article focus } \\
\hline $\begin{array}{l}\text { Specific person's death or } \\
\text { suicidality }\end{array}$ & $5199(81.7)$ & $2245(43.2)$ & $708(13.6)$ & $2246(43.2)$ & $0.88(0.77-1.00)$ & $0.79(0.69-.90)$ \\
\hline Suicide research & $1220(19.2)$ & $549(45)$ & $176(14.4)$ & $495(40.6)$ & $1.06(0.94-1.21)$ & $1.08(0.96-1.23)$ \\
\hline Suicide public policy & $1050(16.5)$ & $412(39.2)$ & $155(14.8)$ & $483(46)$ & $0.80(0.70-0.92)$ & $0.83(0.73-0.95)$ \\
\hline Assisted death & $1123(17.6)$ & $519(46.2)$ & $169(15.0)$ & $435(38.7)$ & $1.13(0.99-1.28)$ & $1.19(1.04-1.36)$ \\
\hline Individual murder-suicide & $483(7.6)$ & $202(41.8)$ & $40(8.3)$ & $241(49.9)$ & $0.92(0.76-1.11)$ & $0.71(0.59-0.86)$ \\
\hline Mass murder-suicide & $131(2.1)$ & $63(48.1)$ & $24(18.3)$ & $44(33.6)$ & $1.19(0.85-1.69)$ & $1.45(1.01-2.09)$ \\
\hline Suicide pact & $131(2.1)$ & $75(57.3)$ & $18(13.7)$ & $38(29.0)$ & $1.74(1.23-2.47)$ & $1.81(1.23-2.64)$ \\
\hline Legal issues related to suicide & $2929(46.0)$ & $1298(44.3)$ & $452(15.4)$ & $1179(40.3)$ & $1.04(0.94-1.15)$ & $1.16(1.05-1.28)$ \\
\hline Suicide as institutional protest & $80(1.3)$ & $36(45)$ & $14(17.5)$ & $30(37.5)$ & $1.05(0.68-1.64)$ & $1.22(0.77-1.92)$ \\
\hline Suicide in fiction & $289(4.5)$ & $128(44.3)$ & $48(16.6)$ & $113(39.1)$ & $0.90(0.68-1.19)$ & $1.07(0.81-1.41)$ \\
\hline \multicolumn{7}{|l|}{ Article type } \\
\hline Opinion column & $952(15.0)$ & $434(45.6)$ & $144(15.1)$ & $374(39.3)$ & $1.09(0.95-1.25)$ & $1.15(1.00-1.32)$ \\
\hline Advice column & $28(0.4)$ & $10(35.7)$ & $1(3.6)$ & $17(60.7)$ & $0.71(0.33-1.55)$ & $0.47(0.22-1.01)$ \\
\hline
\end{tabular}

Note: $\mathrm{Cl}=$ confidence interval, $\mathrm{OR}=$ odds ratio.

*Harmful effect = comparisons of proportion of articles followed by increased suicides v. proportion of articles followed by no change or decreased suicides; ORs > 1 show a harmful effect.

†Protective effect = comparisons of proportion of articles followed by decreased suicides v. proportion of articles followed by no change or increased suicides; ORs < 1 show a protective effect. 
Table 3: Putatively harmful and protective characteristics of articles focusing on suicide in major Toronto publications (2011-2014) and their association with increases or decreases in suicides after publication

Characteristics of media items

\section{Putatively harmful}

Word "suicide" in the headline

Suicide method (in headline)

Suicide method (in text)

Hanging

Self-poisoning

Jumping (from building)

Jumping (from bridge)

Railway

Asphyxia by car exhaust

Asphyxia other than by car exhaust

Firearm

Cutting or stabbing

Drowning

Burning or electrocution

"Suicide by cop"

Assisted death

Other

Method described in detail

Photo (deceased)

Photo (of someone looking sad)

Favourable characteristic (deceased) $\ddagger$

Identifies deceased as a celebrity

Statement that suicide is inevitable

Exciting reporting

Glorified or romanticized suicide

Monocausal explanation for suicide

Statement of approval of suicide

Interview with the bereaved

\section{Putatively protective}

Unfavourable characteristic (deceased) $\ddagger$

Alternatives to suicide

Community resources

Positive outcome of a suicide-related crisis

Warning signs of suicidal behaviour

How to approach someone

Message of hope

$\begin{array}{cccc} & \text { No. of articles } & \text { No. of articles } & \text { No. of articles } \\ \text { followed by } & \text { followed by } & \text { followed by } \\ \text { Total (\%) } & \text { increased } & \text { no change in } & \text { decreased } \\ n=6367 & \text { suicides (\%) } & \text { suicides (\%) } & \text { suicides (\%) }\end{array}$

$754(43.4)$

234 (13.5)

$748(43.1)$

$0.98(0.88-1.10)$

$0.95(0.85-1.06)$

$3153(49.5)$

115 (51.1)

29 (12.9)

$1420(45.0)$

439 (13.9)

758 (11.9)

328 (43.3)

130 (17.2)

$590(9.3)$

265 (44.9)

$74(12.5)$

$219(3.4)$

123 (56.2)

28 (12.8)

248 (3.9)

$110(44.4)$

$41(16.5)$

39 (34.5)

$113(1.8)$

9 (30)

346 (5.4)

$183(52.9)$

824 (12.9)

404 (49.0)

74 (36.8)

201 (3.2)

26 (33.3)

78 (1.2)

52 (41.3)

$126(2.0)$

$27(0.4)$

$13(48.1)$

132 (2.1)

$62(47.0)$

212 (3.3)

$100(47.2)$

812 (12.8)

377 (46.4)

$15(13.3)$

9 (30)

$58(16.8)$

99 (12.0)

23 (11.4)

11 (14.1)

$23(18.3)$

$6(22.2)$

$10(7.6)$

$23(10.8)$

$100(12.3)$

1220 (19.2)

525 (43.0)

162 (13.3)

$257(4.0)$

118 (45.9)

40 (15.6)

669 (10.5)

296 (44.2)

747 (11.7)

367 (49.1)

95 (14.2)

102 (13.7)

4 (9.1)

19 (12.6)

151 (2.4)

$26(59.1)$

$47(0.7)$

60 (39.7)

941 (14.8)

$16(34.0)$

$6(12.8)$

$128(13.6)$

164 (2.6)

$386(41.0)$

$23(14.0)$

1199 (18.8)

75 (45.7)

152 (12.7)

\section{1 (1.4)}

32 (35.2)

1194 (18.8)

$502(42.0)$

$123(1.9)$

$48(39.0)$

85 (1.3)

37 (43.5)

67 (1.1)

32 (47.8)

$13(0.2)$

7 (53.8)

$282(4.4)$

$\begin{array}{ccc}81(36) & 1.36(1.04-1.77) & 1.31(0.99-1.72) \\ 1294(41.0) & 1.11(1.00-1.22) & 1.10(0.99-1.21) \\ 300(39.6) & 0.98(0.84-1.14) & 1.13(0.97-1.32) \\ 251(42.5) & 1.05(0.89-1.25) & 0.98(0.83-1.17) \\ 68(31.1) & 1.68(1.28-2.20) & 1.64(1.23-2.20) \\ 97(39.1) & 1.03(0.79-1.32) & 1.14(0.88-1.48) \\ 59(52.2) & 0.67(0.46-0.99) & 0.66(0.46-0.96)\end{array}$

$119(42.2)$

\section{7 (7.7)}

196 (16.4)

14 (11.4)

11 (12.9)

9 (13.4)

$1(7.7)$

46 (16.3)
$12(40)$

105 (30.3)

$321(39.0)$

104 (51.7)

41 (52.6)

$51(40.5)$

8 (29.6)

60 (45.5)

$89(42.0)$

335 (41.3)

533 (43.7)

99 (38.5)

278 (41.6)

$278(37.2)$

$14(31.8)$

$72(47.7)$

25 (53.2)

427 (45.4)

66 (40.2)

$548(45.7)$

$0.55(0.25-1.20)$

1.47 (1.19-1.83)

$1.28(1.10-1.48)$

0.74 (0.55-0.99)

0.64 (0.40-1.03)

$0.90(0.63-1.29)$

$1.19(0.56-2.54)$

1.14 (0.81-1.61)

1.15 (0.88-1.52)

$1.13(0.98-1.31)$

$0.96(0.85-1.09)$

$1.09(0.85-1.41)$

$1.02(0.87-1.20)$

1.28 (1.10-1.49)

1.86 (1.02-3.41)

0.84 (0.61-1.17)

$0.66(0.36-1.21)$

$0.88(0.76-1.01)$

1.09 (0.80-1.48)

$0.90(0.79-1.02)$

$1.09(0.53-2.27)$

$1.72(1.36-2.17)$

$1.16(1.00-1.35)$

0.67 (0.51-0.89)

$0.65(0.42-1.02)$

1.07 (0.75-1.54)

$1.73(0.76-3.97)$

$0.87(0.62-1.23)$

$1.01(0.76-1.33)$

$1.04(0.90-1.21)$

$0.93(0.82-1.05)$

$1.17(0.91-1.51)$

$1.03(0.87-1.21)$

1.26 (1.08-1.48)

1.57 (0.83-2.96)

$0.79(0.58-1.10)$

$0.64(0.36-1.14)$

$0.86(0.75-0.99)$

$1.08(0.79-1.49)$

$0.84(0.74-0.95)$

52 (57.1)

$0.69(0.45-1.07)$

$0.54(0.36-0.82)$ $496(41.5)$

0.92 (0.81-1.04)

$1.03(0.91-1.17)$

61 (49.6)

$0.82(0.57-1.18)$

$0.74(0.52-1.05)$

37 (43.5)

0.99 (0.64-1.53)

$0.95(0.61-1.46)$

26 (38.8)

$1.18(0.73-1.91)$

$5(38.5)$

$1.50(0.50-4.47)$

$1.15(0.70-1.89)$

1.17 (0.38-3.57)

$117(41.5)$

$0.94(0.74-1.19)$

$1.03(0.81-1.31)$
Harmful effect analysis ${ }^{\star}$

Increased v. no change or decreased suicides, OR (95\% Cl)
Protective effect analysis $\uparrow$

No change or increased $v$. decreased suicides, OR (95\% Cl)

Note: $\mathrm{Cl}=$ confidence interval, $\mathrm{OR}=$ odds ratio

*Harmful effect = comparisons of proportion of articles followed by increased suicides versus proportion of articles followed by no change or decreased suicides; ORs > 1 show a harmful effect. †Protective effect = comparisons of proportion of articles followed by decreased suicides versus proportion of articles followed by no change or increased suicides; ORs $<1$ show a protective effect. ‡Favourable and unfavourable characteristics refer to statements in an article expressing positive or negative value judgments, respectively, about a person's character, personality or behaviour. 
Table 4: Independent associations of characteristics of media articles in major Toronto publications (2011-2014) with increased suicide deaths versus no change or decreased suicide deaths after article publication*

\begin{tabular}{ll} 
Characteristics of media items & OR $(95 \% \mathrm{CI})$ \\
\hline Statement that suicide is inevitable & $1.97(1.07-3.62)$ \\
\hline Asphyxia other than by car exhaust & $1.72(1.36-2.18)$ \\
\hline Jumping (from building) & $1.70(1.28-2.26)$ \\
\hline Suicide pact & $1.63(1.14-2.35)$ \\
\hline Suicide method (in headline) & $1.41(1.07-1.86)$ \\
\hline Firearm & $1.28(1.08-1.51)$ \\
\hline Identifies deceased as a celebrity & $1.27(1.08-1.49)$ \\
\hline Older adults & $1.25(1.03-1.52)$ \\
Suicide public policy & $0.80(0.70-0.94)$ \\
Specific person's death or suicidality & $0.78(0.68-0.90)$ \\
Cutting or stabbing & $0.70(0.52-0.94)$ \\
Note: Cl = confidence interval, OR = odds ratio. & \\
${ }^{*}$ Multivariable logistic regression. &
\end{tabular}

In contrast, the protective effect model confirmed previous findings that describing the suicide deceased negatively, via unfavourable characteristics or as the perpetrator of murder-suicide, was associated with fewer subsequent suicides. ${ }^{14}$ Cutting is a relatively lowlethality method of suicide. Therefore, contagion may be less likely to result in death, and possibly more likely to result in injuries that lead to accessing care. Interviews with people who have attempted suicide show that some may be dissuaded by depiction of certain methods, ${ }^{44}$ perhaps because they are painful or gruesome, which may explain the protective effects of reports about cutting and railway suicide.

The literature on media contagion of suicide in youth is mixed, with some studies supporting contagion ${ }^{21,45-49}$ and others showing a weaker association. ${ }^{11}$ The protective effect model showed that reports related to youth, as well as a specific person's suicidality or suicide and public policy, were independently associated with fewer suicide deaths. We speculate that articles about each may be more likely to contain positive messages about awareness and change, which could mediate protective effects.

A difference between the findings of this study and previous research relates to suicidal ideation. The 2 large previous studies conducted in Austria and Australia found that articles about suicidal ideation were negatively associated with subsequent suicide, ${ }^{5,6}$ whereas no such relationship was seen here.

None of the putatively protective factors we measured were significant even in bivariate comparisons. This may partially be a result of the low base rate of these elements overall, which appear in only $1 \%-4 \%$ of all articles, except for alternatives to suicide, such as seeking treatment, which were included in $18.8 \%$ of articles. The 1 other large study that examined similar factors in an Austrian population generally had higher base rates of protective elements than those seen in the present Canadian study. ${ }^{5}$ Whether these elements may have an impact if they become more frequently used or whether there are any longer-term effects on suicide rates is beyond the scope of the present study.
Table 5: Independent associations of characteristics of media articles in major Toronto publications (2011-2014) with decreased suicide deaths versus no change or increased suicide deaths after article publication*

\begin{tabular}{|c|c|}
\hline Characteristics of media items & OR $(95 \% \mathrm{Cl})$ \\
\hline Unfavourable characteristic $†$ & $0.54(0.35-0.83)$ \\
\hline Railway & $0.62(0.42-0.91)$ \\
\hline Cutting or stabbing & $0.63(0.47-0.84)$ \\
\hline Individual murder-suicide & $0.67(0.54-0.82)$ \\
\hline Specific person's death or suicidality & $0.77(0.66-0.89)$ \\
\hline Suicide public policy & $0.84(0.72-0.97)$ \\
\hline Youth & $0.85(0.75-0.96)$ \\
\hline No. of articles $\ddagger$ (per additional 1 ) & $1.004(1.002-1.005)$ \\
\hline Legal issues related to suicide & $1.16(1.03-1.31)$ \\
\hline Firearm & $1.28(1.09-1.51)$ \\
\hline Older adults & $1.31(1.05-1.63)$ \\
\hline Identifies deceased as a celebrity & $1.32(1.11-1.57)$ \\
\hline Suicide pact & $1.71(1.16-2.54)$ \\
\hline Jumping (from building) & $1.78(1.32-2.39)$ \\
\hline Asphyxia other than by car exhaust & $1.93(1.51-2.48)$ \\
\hline \multicolumn{2}{|c|}{$\begin{array}{l}\text { Note: } \mathrm{Cl}=\text { confidence interval, } \mathrm{OR}=\text { odds ratio. } \\
{ }^{*} \text { Multivariable logistic regression } \\
\text { tUnfavourable characteristics refer to statements in an article expressing negative } \\
\text { value judgments about a person's character, personality or behaviour. } \\
\text { tNumber of articles refers to a count of all articles relating to suicide published } \\
\text { between day - } 14 \text { and day } 0 \text {. }\end{array}$} \\
\hline
\end{tabular}

\section{Limitations}

This study had several key advantages in that it examined both a large number of media articles (nearly 17000 across 13 publications over 4 years) and suicide deaths within a geographically small area with a large population and a well-defined media market. It also tested for both harmful and protective effects. This makes it one of the largest studies to date.

However, it also has several limitations. The most important is that the study could not control how many people were actually exposed to the media items in question; nor could we control the level of exposure. The broad circulation of these publications means we are able to assume that a large proportion of the entire population of Toronto was exposed. However, suicide is a highly complex phenomenon and because this is a large, uncontrolled experiment, we cannot rule out the possibility that the observed associations are a proxy for another kind of exposure. For example, we would expect newspaper reports of suicide to be frequently associated with television news reports or social media activity about the same stories that were not examined as part of this study. Therefore, the relative contribution of each of these exposures is unknown. Additionally, although stories that resulted in more articles were reflected in a larger sample size in the analysis, the study design did not identify or distinguish specific suicide narratives or clusters of articles that may have had more impact.

Media recommendations generally emphasize an itemized list of elements that should and should not be included in suicide-related reports. ${ }^{25-29}$ Accordingly, this study was designed to identify the 
independent association of each specific element with suicides. This approach is scientifically valuable because it supports existing recommendations asserting that, for example, articles that include information about celebrity suicide or about suicide by firearm may be harmful irrespective of potentially harmful or protective elements within the same or other contemporaneous articles. However, a previous study has identified that certain overarching narrative arcs of an article may have differing impacts, ${ }^{5}$ and the same may be the case for clusters of stories about a specific news event. 4,12,14,16,20,21,32 This study design did not test either phenomenon, both of which are relevant for future recommendations and should be the focus of further research in Canada. Moreover, the fact that sensitivity analyses that compared year of publication as well as print and online articles yielded subtle differences (Appendices 3 and 4) underscores the importance of format as well as other contextual factors, not all of which could be controlled for, and some of which may have influenced the results of this study.

Furthermore, most suicides are detected by the Office of the Chief Coroner, but coroner data are imperfect. It is likely that at least $10 \%$ of suicide deaths went unrecognized or were misclassified as being a result of accident or natural causes. ${ }^{50}$

The study examined a single, large Canadian city, and a question remains about the degree to which these results can be generalized to other cities or regions. Likewise, it did not test whether non-suiciderelated articles had any association with suicide rates. Furthermore, this study examined the independent effects of specific media elements on suicide death, but it did not test for interactions between elements (e.g., whether having protective elements in an article might have attenuated the impact of harmful ones). Finally, this study examined only the impact of articles on deaths within 1 week of publication. We chose this method because it is the established standard in the literature ${ }^{5,6}$ and because it provides the best opportunity to observe a potential, acute cause-and-effect relationship. Nonetheless, it may be reasonable to postulate that media reporting could have an impact on suicide deaths months or even years later. ${ }^{51,52}$ Therefore, increases or decreases in suicides shown here may underestimate the full impact of these or other media reports. Likewise, it may be that some elements of the media reports do have effects on suicides, but that these effects are downstream and cannot be detected with this design. For example, it may be that putatively protective factors, such as messages of hope that suicidal thoughts can be overcome, do have a subsequent impact that is not detected within 1 week.

Finally, this study design did not address the question of whether different media reporting characteristics had differing effects on specific demographic groups. Overall associations are of much greater practical importance because journalists formulate their reporting for and disseminate it to the entire public. Nevertheless, investigating differences by subpopulation would add to our understanding and is an important avenue of further study.

\section{Conclusion}

Suicide is a complex phenomenon that is influenced by many factors, of which the media is only one. This large study augments an evolving literature showing that certain elements of media reports highlighted as harmful in Canadian guidelines are associated with increased suicide deaths. The content of media reports - particularly those relat- ing to celebrity suicide, suicide by asphyxia other than by car exhaust, suicide by jumping, suicide pacts and suicide in older adults - may lead to suicide contagion. However, most putatively protective factors had low base rates in the media we analyzed and were not associated with fewer deaths in the following week. Media reporting guidelines have been developed in Canada $^{29}$ and elsewhere ${ }^{23-27}$ to help journalists report respectfully and with attention to concerns about contagion. Future guidelines should take into account these results and those from similar studies in order to provide journalists with the best available evidence on which to base their decisions. Finally, physicians should be mindful of the importance of public messaging about suicide in their interactions with both journalists and patients.

\section{References}

1. Suicide. Geneva: World Health Organization; 2016 [updated 2018]. Available: www.who.int/mediacentre/factsheets/fs398/en/ (accessed 2017 Jan. 16).

2. Gould MS. Suicide and the media. Ann N Y Acad Sci 2001;932:200-21.

3. Hawton K, Williams K. Influences of the media on suicide. BMJ 2002;325:1374-5.

4. Niederkrotenthaler T, Fu KW, Yip PS, et al. Changes in suicide rates following media reports on celebrity suicide: a meta-analysis. J Epidemiol Community Health 2012;66:1037-42.

5. Niederkrotenthaler T, Voracek M, Herberth A, et al. Role of media reports in completed and prevented suicide: Werther v. Papageno effects. Br J Psychiatry 2010;197:234-43.

6. Pirkis JE, Burgess PM, Francis C, et al. The relationship between media reporting of suicide and actual suicide in Australia. Soc Sci Med 2006;62:2874-86.

7. Pirkis J, Blood RW. Suicide and the media. Part I: Reportage in nonfictional media. Crisis 2001;22:146-54.

8. Tousignant M, Mishara B, Caillaud A, et al. The impact of media coverage of the suicide of a well-known Quebec reporter: the case of Gaetan Girouard. Soc Sci Med 2005;60:1919-26.

9. Etzersdorfer E, Voracek M, Sonneck G. A dose-response relationship between imitational suicides and newspaper distribution. Arch Suicide Res 2004;8:137-45.

10. Stack S. Media coverage as a risk factor in suicide. J Epidemiol Community Health 2003;57:238-40.

11. Stack S. Suicide in the media: a quantitative review of studies based on nonfictional stories. Suicide Life Threat Behav 2005;35:121-33.

12. Cheng AT, Hawton $\mathrm{K}$, Lee $\mathrm{C}$, et al. The influence of media reporting of the suicide of a celebrity on suicide rates: a population-based study. Int J Epidemiol 2007;36:1229-34.

13. Bandura A. Self-efficacy: toward a unifying theory of behavioral change. Psychol Rev 1977;84:191-215.

14. Niederkrotenthaler T, Till B, Kapusta ND, et al. Copycat effects after media reports on suicide: a population-based ecologic study. Soc Sci Med 2009;69:1085-90.

15. Till B, Strauss M, Sonneck G, et al. Determining the effects of films with suicidal content: a laboratory experiment. Br J Psychiatry 2015;207:72-8.

16. Fu KW, Chan $\mathrm{CH}$. A study of the impact of thirteen celebrity suicides on subsequent suicide rates in South Korea from 2005 to 2009. PLoS One 2013;8:e53870.

17. Suh S, Chang Y, Kim N. Quantitative exponential modelling of copycat suicides: association with mass media effect in South Korea. Epidemiol Psychiatr Sci 2015;24:150-7.

18. Schäfer M, Quiring $O$. The press coverage of celebrity suicide and the development of suicide frequencies in Germany. Health Commun 2015;30:1149-58.

19. Kim JH, Park EC, Nam JM, et al. The Werther effect of two celebrity suicides: an entertainer and a politician. PLoS One 2013;8:e84876.

20. Ueda M, Mori K, Matsubayashi T. The effects of media reports of suicides by wellknown figures between 1989 and 2010 in Japan. Int J Epidemiol 2014;43:623-9.

21. Gould MS, Kleinman MH, Lake AM, et al. Newspaper coverage of suicide and initiation of suicide clusters in teenagers in the USA, 1988-96: a retrospective, population-based, case-control study. Lancet Psychiatry 2014;1:34-43.

22. Zalsman G, Hawton K, Wasserman D, et al. Suicide prevention strategies revisited: 10-year systematic review. Lancet Psychiatry 2016;3:646-59.

23. Pirkis J, Blood W, Beautrais A, et al. Media guidelines on the reporting of suicide. Crisis 2006;27:82-7.

24. Niederkrotenthaler T, Sonneck G. Assessing the impact of media guidelines for reporting on suicides in Austria: interrupted time series analysis. Aust N Z J Psychiatry 2007;41:419-28.

25. Suicide contagion and the reporting of suicide: recommendations from a national workshop. United States Department of Health and Human Services. MMWR Recomm Rep 1994;43:9-18. Available: www.cdc.gov/mmwr/preview/ mmwrhtml/00031539.htm (accessed 2016 Nov. 11). 
26. Preventing suicide: a resource for media professionals - update 2017. Geneva: World Health Organization; 2017. Available: www.who.int/mental_health/suicide -prevention/resource_booklet_2017/en/ (accessed 2017 Oct. 11).

27. Recommendations for suicide reporting. New York: American Foundation for Suicide Prevention; 2011. Available: http://afsp.org/wp-content/uploads/2016/01/ recommendations.pdf (accessed 2016 Nov. 11).

28. Mindframe. Reporting suicide and mental illness: A Mindframe resource for media professionals. Newcastle (NSW): Hunter Institute of Mental Health; 2014. Available: www.mindframe-media.info/for-media/reporting-suicide?a=10217 (accessed 2016 Nov. 11)

29. Nepon J, Fotti S, Katz LY, et al.; Swampy Cree Suicide Prevention Team. Media guidelines for reporting suicide [policy paper]. Ottawa: Canadian Psychiatric Association; 2009 .

30. Sinyor M, Pirkis J, Picard A, et al. Towards a shared understanding: perspectives from Toronto's first media forum for suicide prevention. Can J Public Health 2016;107:e330-2

31. Sinyor M, Schaffer A, Streiner D. Characterizing suicide in Toronto: an observational study and cluster analysis. Can J Psychiatry 2014;59:26-33.

32. Yip PS, Fu KW, Yang KC, et al. The effects of a celebrity suicide on suicide rates in Hong Kong. J Affect Disord 2006;93:245-52.

33. Chen YY, Tsai PC, Chen PH, et al. Effect of media reporting of the suicide of a singer in Taiwan: The case of Ivy Li. Soc Psychiatry Psychiatr Epidemiol 2010;45:363-9.

34. Cheng ATA, Hawton K, Chen THH, et al. The influence of media coverage of a celebrity suicide on subsequent suicide attempts. J Clin Psychiatry 2007;68:862-6.

35. Cheng ATA, Hawton $\mathrm{K}$, Chen THH, et al. The influence of media reporting of a celebrity suicide on suicidal behavior in patients with a history of depressive disorder. $J$ Affect Disord 2007;103:69-75.

36. Queinec R, Beitz C, Contrand B, et al. Copycat effect after celebrity suicides: results from the French national death register. Psychol Med 2011;41:668-71.

37. Gunnell D, Derges J, Chang SS, et al. Searching for suicide methods: accessibility of information about helium as a method of suicide on the Internet. Crisis 2015;36:325-31.

38. Morii D, Yasusuke M, Nakamae N, et al. Japanese experience of hydrogen sulfide: the suicide craze in 2008. J Occup Med Toxicol 2010;5:28.
39. Marzuk PM, Tardiff K, Hirsch CS, et al. Increase in suicide by asphyxiation in New York City after the publication of Final Exit. N Engl J Med 1993;329:1508-10.

40. Gunnell D, Coope C, Fearn V, et al. Suicide by gases in England and Wales 20012011: evidence of the emergence of new methods of suicide. J Affect Disord 2015;170:190-5.

41. Thomas K, Chang SS, Gunnell D. Suicide epidemics: the impact of newly emerging methods on overall suicide rates - a time trends study. BMC Public Health 2011;11:314.

42. Newspapers: daily readership by age (2016). Pew Research Centre [Washington (DC)] 2016 June 10. Available: www.journalism.org/chart/5802/ (accessed 2017 Mar. 31).

43. Community newspaper readership increases with age. Newspapers Canada [Toronto] 2017 Feb. 15. Available: http://newspaperscanada.ca/news/community -newspaper-readership-increases-age/ (accessed 2017 Apr. 13). 2017]

44. Zahl DL, Hawton K. Media influences on suicidal behaviour: an interview study of young people. Behav Cogn Psychother 2004;32:189-98.

45. Gould MS, Greenberg T, Velting D, et al. Youth suicide risk and preventive interventions: a review of the past 10 years. J Am Acad Child Adolesc Psychiatry 2003;42:386-405.

46. Gould M, Jamieson P, Romer D. Media contagion and suicide among the young Am Behav Sci 2003;46:1269-84.

47. Gould M, Kramer R. Youth suicide prevention. Suicide Life-Threat Behav 2001;31(Suppl):6-31.

48. Gould M, Wallenstein S, Kleinman M, et al. Suicide clusters: an examination of age-specific effects. Am J Public Health 1990;80:211-2, February.

49. Shoval G, Zalsman G, Polakecitch J, et al. Effect of the broadcast of a television doc umentary about a teenager's suicide in Israel on suicidal behavior and methods. Crisis 2005;26:20-4.

50. Tøllefsen IM, Helweg-Larsen K, Thiblin I, et al. Are suicide deaths under-reported? Nationwide re-evaluations of 1800 deaths in Scandinavia. BMJ Open 2015;5:e009120.

51. Fu KW, Yip PS. Long-term impact of celebrity suicide on suicidal ideation: results from a population-based study. J Epidemiol Community Health 2007;61:540-6.

52. Sinyor M, Schaffer A, Redelmeier DA, et al. Did the suicide barrier work after all?: revisiting the Bloor Viaduct natural experiment and its impact on suicide rates in Toronto. BMJ Open 2017;7:e015299.
Competing interests: All authors report no financial relationships with commercial interests of relevance to this study. Mark Sinyor reports receiving grant support from the American Foundation for Suicide Prevention, the Physicians' Services Incorporated Foundation, the Dr. Brenda Smith Bipolar Fund, the University of Toronto Department of Psychiatry Excellence Fund and the Innovation Fund of the Alternative Funding Plan from the Academic Health Sciences Centres of Ontario. Jane Pirkis reports that she has received grant support from the American Foundation for Suicide Prevention. No other competing interests were declared.

This article has been peer reviewed.

Affiliations: Department of Psychiatry, Sunnybrook Health Sciences Centre and Department of Psychiatry, University of Toronto (Sinyor); Mood and Anxiety Disorders Program, Department of Psychiatry, Sunnybrook Health Sciences Centre and Department of Psychiatry, University of Toronto (Schaffer); Department of Psychiatry (Nishikawa), Sunnybrook Health Sciences Centre; University of Toronto and Evaluative Clinical Sciences at the Sunnybrook Research Institute, Division of General Internal Medicine, Sunnybrook Health Sciences Centre, and Institute for Clinical Evaluative Sciences (Redelmeier), Toronto, Ont.; Public Health, Medical University of Vienna, Center for Public Health, Department of Social and Preventive Medicine, Suicide Research Unit (Niederkrotenthaler), Vienna, Austria; Departments of Psychiatry, Psychology and Community Health Sciences (Sareen), University of Manitoba, Winnipeg, Man.; Department of Psychiatry, Sunnybrook Health Sciences Centre and Department of Psychiatry (Levitt), University of Toronto; Evaluative Clinical Sciences, Hurvitz Brain Sciences Program, Sunnybrook Research Institute and Department of Health Policy, Management and Evaluation, University of Toronto (Kiss), Toronto, Ont.; Centre for Mental Health, Melbourne School of Population and Global Health and University of Melbourne (Pirkis), Melbourne, Australia

Contributors: Mark Sinyor had full access to all of the data in the study and takes responsibility for the integrity of the data and the accuracy of the data analysis. Mark Sinyor, Ayal Schaffer, Donald Redelmeier, Thomas Niederkrotenthaler, Jitender Sareen, Anthony Levitt and Jane Pirkis contributed to the conception and design of the work. Mark Sinyor, Yasunori Nishikawa and Alex Kiss performed the statistical analysis. All authors contributed to the acquisition and interpretation of the data. Mark Sinyor drafted the manuscript and obtained funding. All authors revised the manuscript critically for important intellectual content and agreed to be accountable for all aspects of the work.
Funding: This study was supported by the American Foundation for Suicide Prevention (YIG-0-035-13). The sponsor had no role in the design and conduct of the study; collection, management, analysis and interpretation of the data; preparation, review or approval of the manuscript; and decision to submit the manuscript for publication.

Data sharing: None of the data presented here are publicly available.

Acknowledgements: The authors thank the American Foundation for Suicide Prevention for its generous grant support for this project. They also thank Dr. James Edwards (regional supervising coroner for Toronto East) and the entire staff at the Office of the Chief Coroner of Ontario, including Andrew Stephen, for making this research possible. The authors further thank Infomart for providing and coding the media data.

Disclaimer: Donald Redelmeier is a member of the CMAJ Governance Council and was not involved in the editorial decision-making process for this article.

Accepted: May 25, 2018.

Correspondence to: Mark Sinyor, mark.sinyor@sunnybrook.ca 